\title{
Transient adenoviral gene transfer of Smad7 prevents injury-induced epithelial-mesenchymal transition of lens epithelium in mice
}

Shizuya Saika ${ }^{1}$, Kazuo Ikeda ${ }^{2}$, Osamu Yamanaka ${ }^{1}$, Misako Sato ${ }^{3}$, Yasuteru Muragaki ${ }^{3}$, Yoshitaka Ohnishi ${ }^{1}$, Akira Ooshima ${ }^{3}$, Yuji Nakajima ${ }^{2}$, Kazuhiko Namikawa ${ }^{4}$, Hiroshi Kiyama ${ }^{4}$, Kathleen C Flanders ${ }^{5}$ and Anita B Roberts ${ }^{5}$

${ }^{1}$ Department Ophthalmology, Wakayama Medical University, Kimiidera, Wakayama, Japan; ${ }^{2}$ Department Anatomy, Graduate School of Medicine, Osaka City University, Japan; ${ }^{3}$ Department of Pathology, Wakayama Medical University, Kimiidera, Wakayama, Japan; ${ }^{4}$ Department of Anatomy/Neurobiology, Graduate School of Medicine, Osaka City University, Japan and ${ }^{5}$ Laboratory of Cell Regulation and Carcinogenesis, National Cancer Institute, National Institutes of Health, Bethesda, MD, USA

\begin{abstract}
We examined the effect of adenovirus-mediated transient expression of Smad7, an inhibitory Smad in TGF $\beta$ I activin signaling, on injury-induced epithelial-mesenchymal transition (EMT) of lens epithelium in mice. A volume of $3 \mu \mathrm{l}$ of adenoviral solution was injected into the right lens of adult male C57BL/6 mice $(n=56)$ at the time of capsular injury made using a hypodermic needle under general anesthesia. A mixture of recombinant adenovirus carrying CAG promoter-driven Cre (Cre adv) and mouse Smad7 complementary DNA (Smad7 adv) was administered to induce Smad7 expression, while control lenses were treated with Cre adv alone. After healing intervals of 2, 3, 5, and 10 days, animals were killed $2 \mathrm{~h}$ after labeling with bromodeoxyuridine (BrdU) and eyes were processed for histology. During healing, marked expression of Smad7 was observed in lens epithelial cells in the Smad7 adv group with loss of nuclear translocation of Smads2/3, while little Smad7 and abundant nuclear Smads2/3 were seen in cells in the Cre adv group. Lens epithelial cells in the Cre adv control group exhibited a fibroblastic appearance at days 5 and 10 and the capsular break was sealed with fibrous tissue, while Smad7 adv-treated cells around the capsular break retained their epithelial morphology and the break was not sealed. Expression of snail mRNA, and $\alpha$-smooth muscle actin, lumican, and collagen VI proteins, markers of EMT, was observed in control-treated eyes, but not in cells of the Smad7 adv group at day 5 with minimal expression at day 10. Additionally, cell proliferation increased in epithelium infected with Smad7 adv consistent with suppression of injury-induced upregulation of TGF $\beta 1$ in epithelium. We conclude that gene transfer of Smad7 in mice prevents injury-induced EMT of lens epithelial cells and sealing of the capsular break with fibrous tissue.
\end{abstract}

Laboratory Investigation (2004) 84, 1259-1270, advance online publication, 19 July 2004; doi:10.1038/labinvest.3700151

Keywords: Iens epithelial cell; epithelial-mesenchymal transition; transforming growth factor $\beta$; Smad; mouse

Following injury, lens epithelial cells undergo epithelial-mesenchymal transition (EMT), ${ }^{1-4}$ which contributes to the formation of fibrotic tissue in the injured lens. ${ }^{5-8}$ A similar phenomenon is observed in the human lens capsule following cataract extraction and implantation of an artificial intra-

Correspondence: Dr S Saika, MD, PhD, Department of Ophthalmology, Wakayama Medical University, 811-1 Kimiidera, Wakayama 641-0012, Japan.

E-mail: shizuya@wakayama-med.ac.jp

Received 22 April 2004; revised and accepted 20 May 2004; published online 19 July 2004 ocular lens. Such an EMT-related fibrotic reaction is clinically unfavorable since it may cause opacification and contraction of the remaining anterior lens capsule, as well as opacification in the posterior capsule, all of which potentially impair vision. Eye aqueous humor contains abundant transforming growth factor $\beta 2$ (TGF $\beta 2)^{9,10}$ and evidence suggests that TGF $\beta$ is involved in injury-related EMT in lens epithelial cells. ${ }^{11-14}$ We have shown that endogenous TGF $\beta 2$ induces a transient nuclear translocation of the TGF $\beta$ signaling intermediates, Smads $3 / 4$ in lens epithelial cells postinjury in mice, which was inhibited by local administration of a neutralizing 
antibody against TGF $\beta 2$, indicating that this growth factor isoform is responsible for the activation of Smads3/4 signaling in lens epithelium. ${ }^{7}$ Human lens epithelial cells are also regulated by TGF $\beta /$ Smad signaling in vivo during wound healing. ${ }^{15} \mathrm{We}$ recently reported that $\mathrm{TGF} \beta / \mathrm{Smad} 3$ signaling is critical in the induction of EMT in lens or renal epithelium in vivo by showing that EMT is blocked in Smad3-null mice, ${ }^{16,17}$ although in vitro studies suggest that a variety of signaling pathways may be required for EMT. ${ }^{18-23}$

Smad7 is an inhibitory Smad that interferes with Smad signaling by preventing the phosphorylation of Smads2/3, which normally occurs following binding of TGF $\beta /$ activin to their cell surface receptors. $^{24-27}$ Recently, transient introduction of the Smad7 gene using an adenovirus vector has been shown to be effective in treating tissue inflammatory/fibrotic disorders in lung, ${ }^{28}$ kidney,${ }^{29}$ and liver. ${ }^{30}$ Therefore, we hypothesized that transfer of Smad7 complementary DNA (cDNA) using a viral vector might also block injury-induced EMT in lens epithelial cells. In the present study, we created an adenoviral gene-transfer system to introduce Smad7 cDNA into an injured mouse lens and show that transient adenoviral gene transfer effectively blocks injury-induced EMT in lens epithelium while enhancing cell proliferation. These results suggest a potential therapeutic efficacy of Smad7 gene transfer in the treatment of postoperative capsular fibrosis.

\section{Materials and methods}

All the experimental procedures were approved by both the DNA Recombinant Experiment Committee and Animal Care and Use Committee of Wakayama Medical University, Wakayama, Japan, and conducted in accordance with the Association for Research in Vision and Ophthalmology Statement for the Use of Animals in Ophthalmic and Vision Research.

\section{Adenovirus Vector Construction and Virus Purification}

We used the Adenovirus Cre/LoxP-Regulated Expression Vector Set (\#6151, Takara, Tokyo, Japan) to generate recombinant adenovirus. Cosmid pAxCALNLmSmad7 was constructed by the insertion of mouse Smad7 cDNA (a kind gift by Dr K Miyazono, The University of Tokyo School of Medicine, Tokyo, Japan) into the Swa I cloning site of pAxCALNLw. ${ }^{31}$ Using the COS-TPC method, ${ }^{32}$ recombinant adenovirus of AxCALNLmSmad7 was generated by transfecting 293 cells with $\mathrm{pAx}$ CALNLSmad7. AxCANCre was generated by transfecting 293 cells with Ax-CALNLCreDNA-TPC as described in the manufacturer's protocol. The titer of recombinant adenoviruses was measured by the $50 \%$ tissue culture infectious dose method. ${ }^{33}$ Each adenovector was used at the concentration of $2 \times 10^{7} \mathrm{PFU} / \mu$ l. When these two viral vectors coinfect cells, Cre recombinase expressed under the CAG promoter (cytomegalovirus enhancer, chicken $\beta$ actin promoter plus a part of $3^{\prime}$ untranslated region of rabbit $\beta$-globin) activates the stuffer PolyA through the Cre/LoxP system.

\section{Experimental Protocol}

Evaluation of the efficacy of adenoviral gene transfer was performed by coinfection of viruses carrying Cre recombinase under the CAG promoter and LNLgreen fluorescent protein (GFP) or by infection of virus carrying GFP alone in an injured lens. The anterior lens capsule of the right eye of an adult C57BL/6 mouse was punctured as previously reported under general anesthesia by intraperitoneal (i.p.) pentobarbital. ${ }^{7,17}$ A volume of Three $3 \mu$ l of viral vector solution of either group was injected into the injured lens at the time of capsular injury. At days 1,2 , and $5(n=2$ /group on each day) following injury, the right eye was enucleated and embedded in OCT compound. Cryosections $(7 \mu \mathrm{m})$ were examined without fixation under fluorescence microscopy.

Upon confirmation of the expression of GFP in injured lens epithelial cells, we introduced Smad7 cDNA. One vector expresses Cre under the CAG promoter (CAG-Cre) while the other contains Smad7 that is activated by Cre recombinase (LNL-Smad7). The right eyes of 4 -week-old male C57BL/6 mice $(n=56)$ were used. To induce transcription of Smad7, both LNL-Smad7 and CAG-Cre vectors (3 $\mu$ l total) were coinfected directly into the affected lens at the time of formation of a break in the anterior capsule as described above. Control lenses were treated with CAG-Cre alone $(3 \mu \mathrm{l})$. At days 2 ( $n=3$ /group), 3 ( $n=3$ /group), 5 ( $n=11$ /group), and 10 ( $n=11 /$ group), post-treatment, the eyes were enucleated, fixed, and embedded in paraffin as previously reported. ${ }^{7,17}$

\section{In Situ Hybridization for Snail}

Snail is a member of a family of zinc-fingercontaining transcriptional repressors increasingly associated with suppression of the epithelial phenotype associated with EMT. ${ }^{34-36}$ Digoxigenin-labeled riboprobes for mouse snail and were prepared using a digoxigenin-labeling kit (Roche Diagnostics Corp-Boehringer Mannheim, Indianapolis, IN, USA). and in situ hybridization of paraffin sections (5 $\mu \mathrm{m}$ ) was carried out as previously reported..$^{16,17}$

\section{Immunohistochemistry}

Deparaffinized sections $(5 \mu \mathrm{m})$ were reacted with primary antibodies appropriately diluted with phos- 
phate-buffered saline (PBS) following blocking with $5 \%$ dried milk and $5 \%$ serum as previously reported. After washing in PBS, the specimens were treated with fluorescein isothiocyanate (FITC)-conjugated secondary antibodies. Primary antibodies against phosphorylated Smad2 (1:50 dilution, Chemicon, Temecula, CA, USA), Smad3 (1:100 dilution, Zymed, South San Francisco, CA, USA), Smad7 (1:400 dilution, Santa Cruz Biotechnology, Santa Cruz, CA, USA, \#sc-7004), $\alpha$-smooth muscle actin $(\alpha$ SMA) (1:200 dilution, Neomarker, Fremont, CA,USA), TGF $\beta 1$ (intracellular and extracellular forms), TGF $\beta 2$, lumican, and collagen type VI (1:200 dilution, Southern Biotechnology, Birmingham, AL, USA) were used as previously reported. ${ }^{16,37}$ BrdU immunostaining was performed as previously described. ${ }^{38}$ In brief, deparaffinized sections were treated with $2 \mathrm{~N} \mathrm{HCl}$ for $1 \mathrm{~h}$ at $37^{\circ} \mathrm{C}$, treated with anti-BrdU antibody (1:11 dilution in PBS, Roche Diagnostics, Mannheim, Germany) and then with peroxidase-conjugated secondary antibody after washing in PBS. Following the color reaction with diaminobenzidine and methyl green counterstaining, the number of labeled cells in healing epithelia was determined. Six specimens were counted in each group at days 5 and 10. Histology was observed by staining tissues with hematoxylin and eosin (HE).

\section{Results}

Efficacy of Adenovirus-Mediated Expression of GFP in Injured Lens Epithelial Cells

We confirmed that the CAG-Cre/LoxP system can efficiently introduce a gene of interest by observing the expression of GFP. When the injured lens epithelium was coinfected with adenoviral vectors encoding Cre under control of the CAG promoter and GFP under control of the LNL promoter, green fluorescence was observed at day 1 and later in lens epithelium, as well as in corneal endothelium and iris tissue (Figure 1a,b). No fluorescence was detected in eyes infected with CAG-Cre adv only.

\section{Smad7 Expression and Inhibition of Smad3 Signaling}

Our previous study showed that nuclear translocation of Smad proteins in lens epithelial cells following injury generally occurs before the cells form multilayers, but is also occasionally observed in the multilayers. At day 2 after infection, phosphorylated Smad2 (not shown) and Smad3 were detected in the nuclei of lens epithelial cells in the anterior lens adjacent to the capsular break (Figure 1c, d) in control eyes, whereas in Smad7-infected eyes phospho-Smad2 (not shown) was not detected and Smad3 was seen only faintly in the cytoplasm of the anterior lens (Figure 1e,f). A similar phenomenon was also observed even in the equatorial region apart from the injury site at the same time point.
Smad3 was detected in the nuclei of lens epithelial cells in the equatorial lens region (Figure 1g, h) in a control specimen, but not in the equatorial epithelia of the Smad7-infected group (Figure 1i,j). At and after day 5 , the majority of nuclei were negative for both Smads 2/3 in the control, and in Smad7 advtreated specimens (not shown). Smad7 protein, presumably the translated product derived from exogenously introduced Smad7 cDNA, was strongly detected in the healing lens epithelium from day 2 onward, while faint immunoreactivity for endogenous Smad7 was seen in the healing lens epithelium in the control group for up to 10 days (Figure 1k, l).

\section{Histology of Injured Lens Epithelial Cells and Expression of EMT Markers}

HE staining showed that the capsular break was sealed by a plaque of elongated, fibroblast-like, lens epithelial cells as early as day 5 (Figure 2a) in CAG/ Cre-infected eyes, whereas the capsular opening was not closed at day 5 (Figure 2b) in the Smad7-infected group and remained open at day 10 (Figure 2c, d). Rather, the Smad7-infected group showed round or ovoid epithelial-like cells surrounding the break. This finding strongly suggests that introduction of exogenous Smad7 cDNA inhibited EMT following injury.

To test this hypothesis, we first carried out in situ hybridization for snail mRNA in paraffin sections. Snail is a member of a family of zinc-fingercontaining transcriptional repressors increasingly associated with suppression of the epithelial phenotype associated with EMT. The results showed that, as previously reported, uninjured lens epithelium does not express snail mRNA (data not shown). Snail mRNA is upregulated in the injured lens epithelium of the control Cre adv-treated group (Figure 3a), whereas eyes treated with Smad7 adv showed no expression of snail in injured epithelium at day 5 (Figure 3b). At day 10, its expression in lens cells seemed to increase further (Figure 3c) in the control Cre adv-treated group, while only faint expression of snail was detected in the cells of Smad7 adv-treated specimens (Figure 3d). No specific signal was detected in specimens labeled with the sense probe (Figure 3e).

To examine if snail expression is followed by EMT, we immunostained tissues with antibodies against specific markers for EMT, for example, $\alpha \mathrm{SMA}$, lumican, and collagen type VI. The results showed that there was no expression of $\alpha \mathrm{SMA}$ in lens epithelial cells at 2 days postinjury in eyes of either the Smad7 adv-treated group or the control group. However, at day 5, marked immunofluorescence for $\alpha$ SMA was seen in multilayered cells in the control CAG/Cre adv-treated lens (Figure 4a), but almost never in cells of Smad7 adv-treated lenses (Figure 4b). At day 10, a strong immunofluorescence for $\alpha \mathrm{SMA}$ was seen in control CAG/Cre group cells 

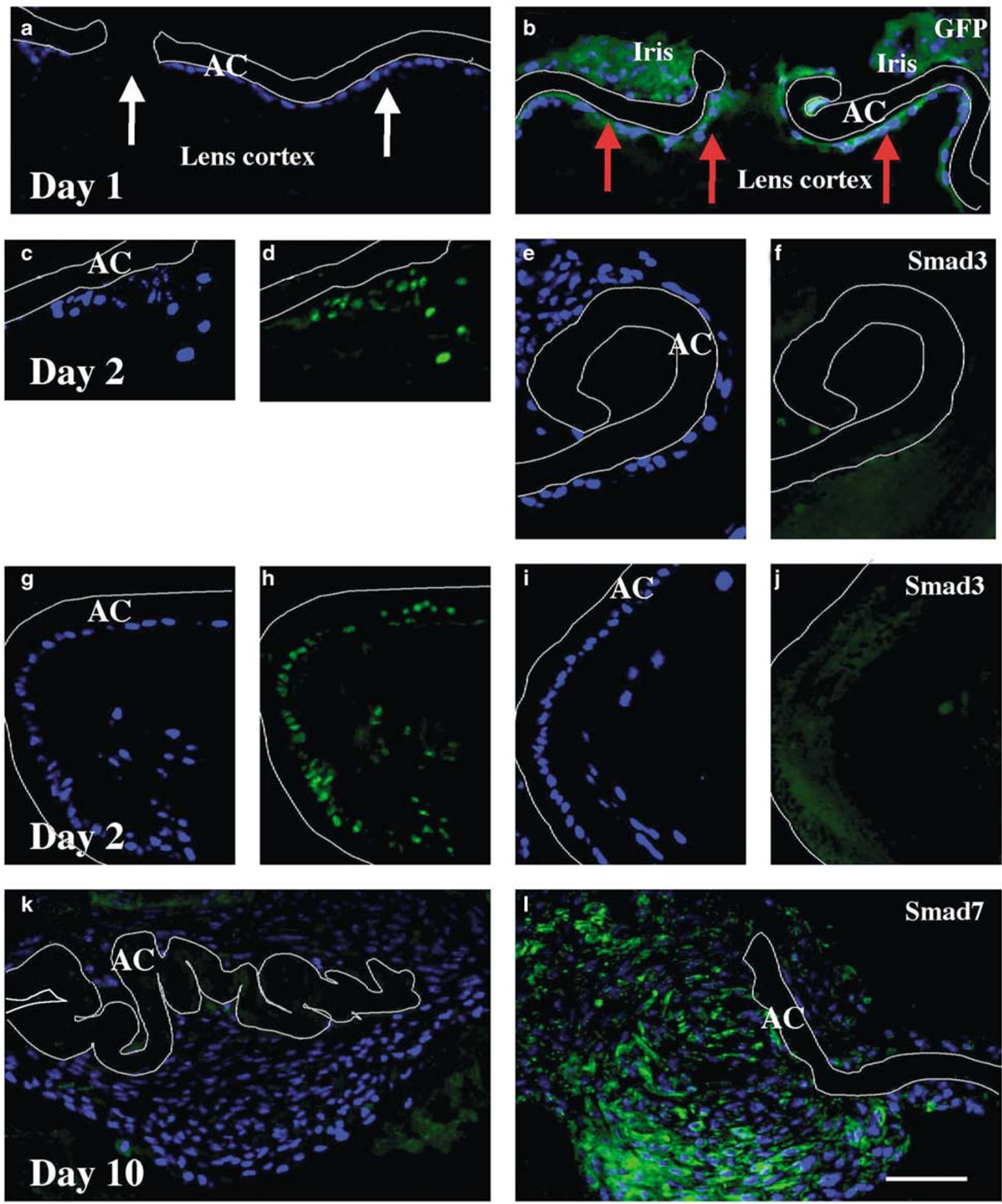

Figure 1 Detection of GFP, Smad3, or Smad7 by fluorescence in injured lens epithelium at day 1, 2, or 10. Expression of GFP was examined in an injured mouse lens coinfected with viruses carrying Cre under the CAG promoter and LNL-GFP or infected only with virus containing CAG/Cre. GFP expression is observed in coinfected lens epithelium (b, red arrows), but not in epithelium without GFPcarrying virus (a, white arrows). At day 2, Smad3 is detected in the nuclei of lens epithelial cells located adjacent to the capsular break (d) and lens equator (h) in a control, CAG/Cre- adenovirus-infected specimen, while faint cytoplasmic expression of Smad3 is observed in the injured lens epithelium adjacent to the break (f) and in the equator (j) in eyes coinfected with CAG/Cre-carrying and LNL/Smad7carrying adenoviruses. Very faint endogenous Smad7 expression is observed in CAG/Cre-carrying adenovirus-infected specimen at day $10(\mathbf{k})$, while prominent immunoreactivity for presumably exogenous Smad7 is seen in the cell multilayer formed in an injured lens coinfected with CAG/Cre-carrying adenovirus and LNL/Smad7-carrying adenovirus (l). Frames $\mathbf{c}$, e, g, and i, indicate localization of nuclei as stained with DAPI in the frames $\mathbf{d}, \mathbf{f}, \mathbf{h}$, and $\mathbf{j}$, respectively. Dotted lines indicate anterior capsule. AC, anterior lens capsule; bar, $50 \mu \mathrm{m}$. 

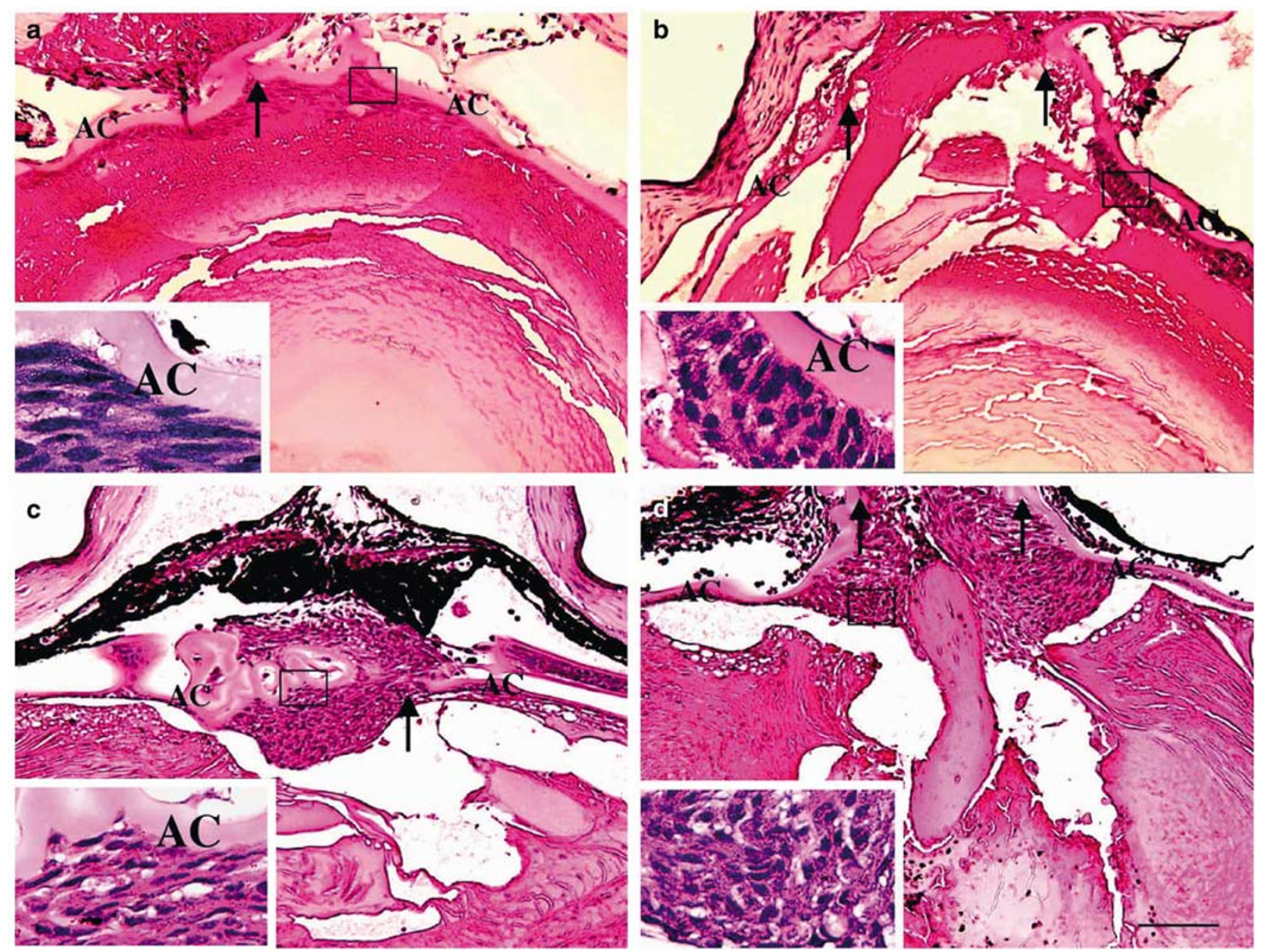

Figure 2 Histology by HE staining of injured lenses at days 5 and 10. Frames a and $\mathbf{b}$ show histology of the specimens at day 5 , and frames $\mathbf{c}$ and $\mathbf{d}$ at day 10. HE staining show that the capsular break was sealed by a plaque of elongated, fibroblast-like, lens epithelial cells in control, CAG/Cre-carrying adenovirus-infected specimens (a, c), whereas the capsular opening was not closed with relatively round or ovoid, epithelial-like, lens cells in eyes coinfected with CAG/Cre-carrying adenovirus and LNL/Smad7-carrying adenovirus (b, d). Inset in each frame is a high-magnification picture of the rectangular area. Arrows, edge of the broken capsule. Bar, $100 \mu \mathrm{m}$; $16 \mu \mathrm{m}$ (insets).

(Figure 4c), whereas faint immunoreactivity was detected in lens epithelial cells in the multilayer around the capsular break in the Smad7 adv-treated group (Figure $4 \mathrm{~d}$ ).

We then examined the expression of lumican and collagen type VI, components of fibrotic tissue, at days 5 and 10 postinjury. As expected, the results indicated that fibroblast-like lens epithelial cells were labeled with antilumican and anticollagen type VI only in the control group, and not in Smad7 adv-treated specimens (Figure 5).

\section{Epithelial Cell Proliferation}

The TGF $\beta /$ Smad pathway is potentially involved in suppression of cell proliferation in many organs/ tissues. We used BrdU incorporation to evaluate cell proliferation in the healing epithelium following exogenous Smad7 gene transfer. Epithelial cell proliferation was much higher in the Smad7 adenovirus group than in the Cre adenovirus group at day 5, but not at day 10 (Figure 6). At day 5 BrdUlabeled cells were induced in both the equatorial and anterior epithelia in the Smad7 adenovirus group.

\section{Expression of TGF $\beta 1$ and TGF $\beta 2$}

Since introduction of the Smad7 gene blocked injury-induced EMT in lens epithelial cells, we examined if this expression suppresses injuryinduced upregulation of TGF $\beta 1$ in lens epithelial cells. Uninjured lens epithelium expresses immunoreactive TGF $\beta 2$ in its mid-peripheral region, but does not express TGF $\beta 1$. Fibroblast-like, multilayered epithelial cells adjacent to the capsular break in the control group showed increased expression of TGF $\beta 1$ following injury, whereas 

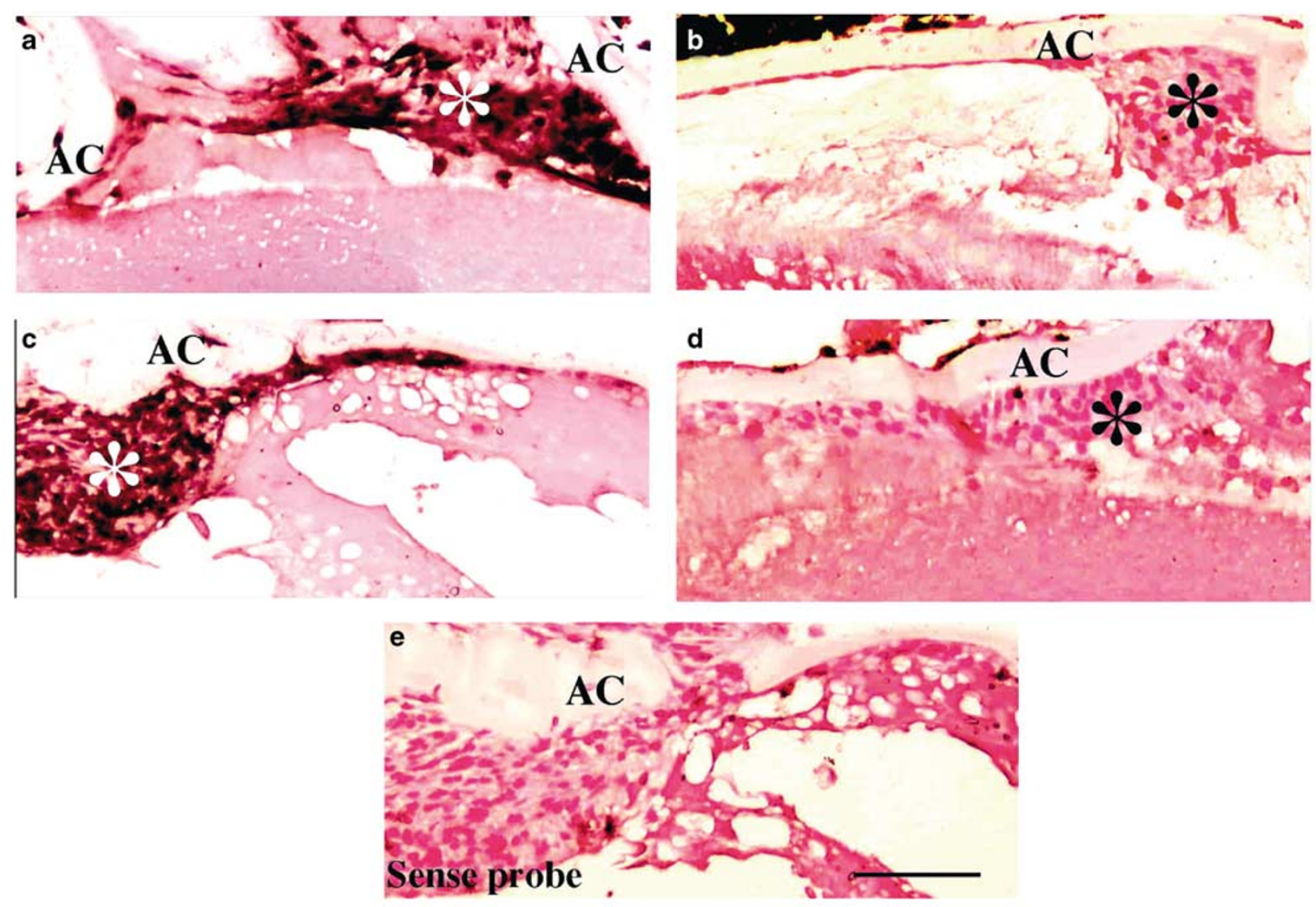

Figure 3 Expression of snail mRNA in injured lens epithelium as detected by in situ hybridization. The uninjured lens epithelium does not express snail mRNA (data not shown). Injured lens epithelium upregulates snail mRNA at day 5 (a) and then its expression increases at day 10 (c), whereas Smad7 gene introduction abolishes snail expression in injured epithelium at day 5 (b) with very faint snail expression being detected in the cells of Smad7 vector-treated specimens at day 10 (d). No specific signal was detected in specimens labeled with the sense probe (e). White or black asterisks indicate the cell multilayers composed of fibroblastic lens cells that are labeled for snail mRNA or lens cell masses without snail mRNA labeling. AC, anterior capsule, bar, $40 \mu \mathrm{m}$.

multilayered cells in the Smad7 gene-transfer group were not labeled for either intracellular or extracellular TGF $\beta 1$ (Figure $7 \mathrm{a}-\mathrm{d}$ ). In the control group, TGF $\beta 2$ immunoreactivity was reduced in fibroblastic lens cells generated through EMT, which accumulated around the capsular break at days 5 and 10 (Figure 7e). In the Smad7 adv-treated group, multilayered lens cells were of epithelial shape and were still markedly labeled for TGF $\beta 2$ (Figure 7f).

\section{Discussion}

The present study shows that transient adenoviral gene transfer of Smad7 cDNA prevents injuryinduced EMT in lens epithelial cells in association with enhancement of cell proliferation in mice in vivo. Introduction of Smad7 also abolishes upregulation of snail, $\alpha$ SMA and extracellular matrix components. Smad7 blocks signaling from both Smad2 and Smad3 and activated Smads 2 and 3 have distinct roles in gene regulation based upon the results of gene-expression array studies. ${ }^{39,40}$ Moreover, it has been reported that conversion of fibroblasts to $\alpha$ SMA-expressing myofibroblasts depends on Smad2, but that expression of extracellular matrix components, that is, collagen types, is Smad3-dependent. ${ }^{41-43}$ However, EMT, a process of phenotypic conversion from an epithelial cell type to a myofibroblastic cell type, is believed to differ mechanistically from that of fibroblast-myofibroblast conversion. We previously showed that Smad3 signaling is required for injury-induced EMT of lens epithelial cells and renal tubular epithelial cells, ${ }^{16,17}$ but not for generation of myofibroblasts from fibroblasts in healing dermal tissue. ${ }^{37}$ These and other data suggest that Smad3 is required in the very early phases of injuryinduced EMT, whereas Smad2 might be important in the later phases of the process. Introduction of the Smad7 gene blocks injury-induced EMT in lens epithelial cells possibly via blocking Smad3 signaling.

Transient introduction of the Smad7 gene by using an adenoviral vector is reportedly effective 

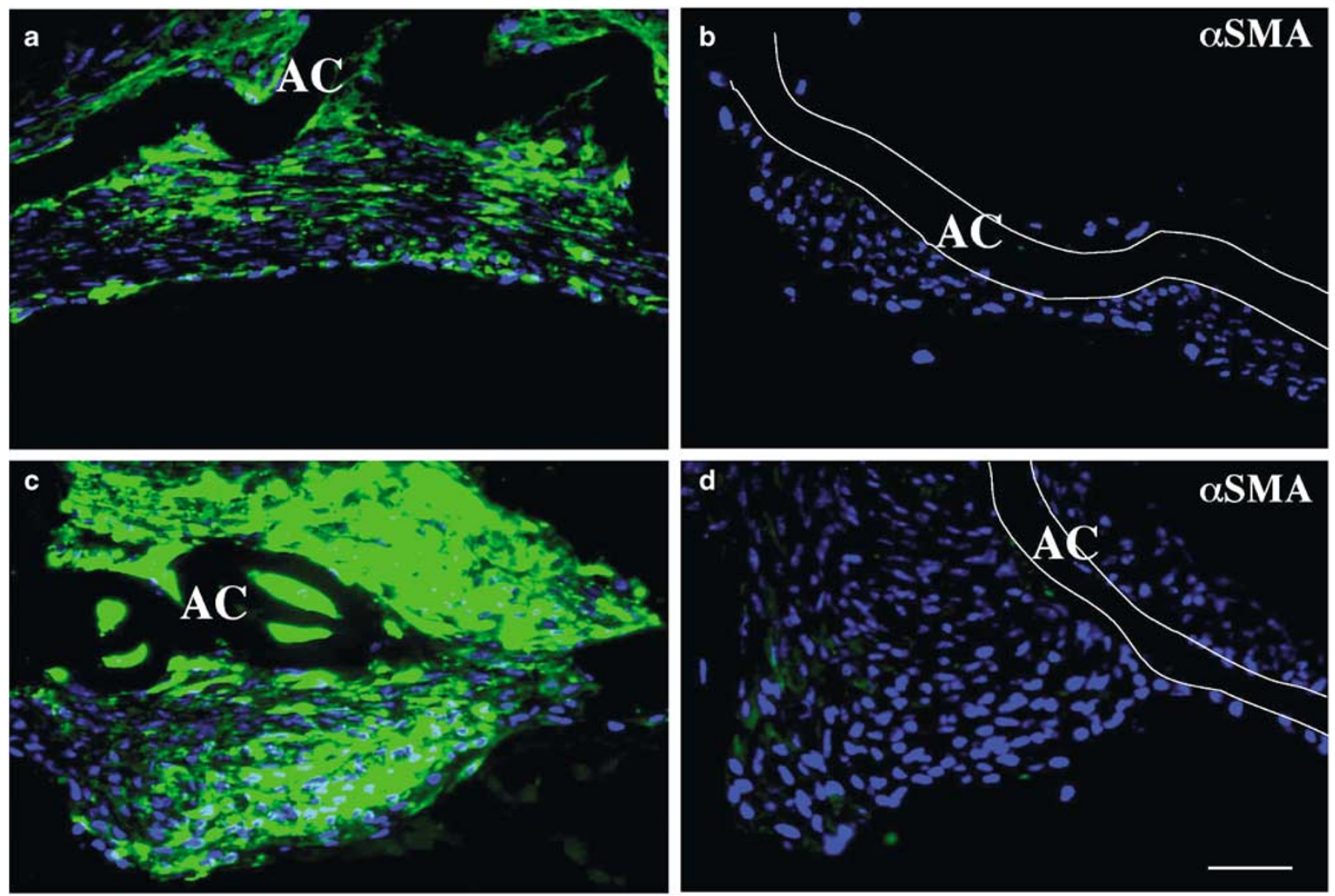

Figure 4 Expression of $\alpha$ SMA in epithelial cells of the injured lens. Frames a and $\mathbf{b}$ show staining of the specimens at day 5 , and frames $\mathbf{c}$ and $\mathbf{d}$ at day 10. At days 5 and 10, multilayered lens epithelial cells in control, CAG/Cre-carrying adenovirus-infected specimens, are markedly labeled with anti- $\alpha$ SMA antibody $(\mathbf{a}, \mathbf{c})$, while at day 5 no $\alpha$ SMA immunoreactivity is detected in epithelial cells of the lens coinfected with CAG/Cre-carrying adenovirus and LNL/Smad7-carrying adenovirus (b) and faint $\alpha$ SMA immunoreactivity is observed in these cells at day 10 (d). Dotted lines indicate anterior capsule; bar, $40 \mu \mathrm{m}$.

in treating inflammatory/fibrotic disorders in lung, kidney, and liver. ${ }^{28-30}$ In these tissues, Smad7 gene transfer not only suppresses the conversion of interstitial fibroblasts (including liver stellate cells) to aSMA-expressing myofibroblasts, but also inhibits extracellular matrix expression. While, the mechanism of generation of $\alpha$ SMA-positive myofibroblasts might differ among organs, ${ }^{44,45}$ it would be blocked by Smad7 gene transfer even if it was a Smad2-dependent process. Blocking TGF $\beta$ action at the receptor level may block various signaling cascades potentially activated upon ligand binding to the receptor, such as MAP kinase pathways in addition to Smad signaling. Blocking injury-induced EMT of lens epithelium by Smad7 gene transfer, or by knocking out Smad3, indicates it is not necessary to block non-Smad TGF $\beta$ signaling to suppress EMT.

Our previous study in lens epithelial cells showed that loss of Smad3 results in the abrogation of upregulation of TGF $\beta 1$ and extracellular matrix components, which was mimicked by gene transfer of Smad7 into the lens in the present study. In contrast, expression of TGF $\beta 2$ in the peripheral epithelium of an injured lens and in the central epithelium around the capsular break was similar in the Cre- and Smad7-treated groups, consistent with the observation that autoinduction of TGF $\beta 1$, but not expression of TGF $\beta 2$, is dependent upon Smad3.

The TGF $\beta /$ Smad pathway is also potentially involved in regulation (mainly suppression) of cell proliferation in many organs/tissues. ${ }^{24}$ We show here that Smad7 overexpression enhances the injury-induced proliferation of lens epithelial cells. Interestingly, this was not observed following lens injury in Smad3-null mice. ${ }^{17}$ Since loss of Smad3 alone does not affect cell proliferation in an injured lens, ${ }^{17}$ it suggests that inhibition of cell proliferation in the injured lens epithelium might require either Smad2 or both Smad2 and Smad3, possibly in cooperation with Smad-independent pathways. We have also observed that loss of Smad3 does not affect cell proliferation in the injured corneal epithelium (S Saika, WW-Y Kao, AB Roberts, unpublished data, 2003), whereas it stimulates keratinocyte proliferation following epidermal injury ${ }^{46}$ indicating that regulation of cell proliferation by TGF $\beta /$ Smad signaling is tissue-specific. 

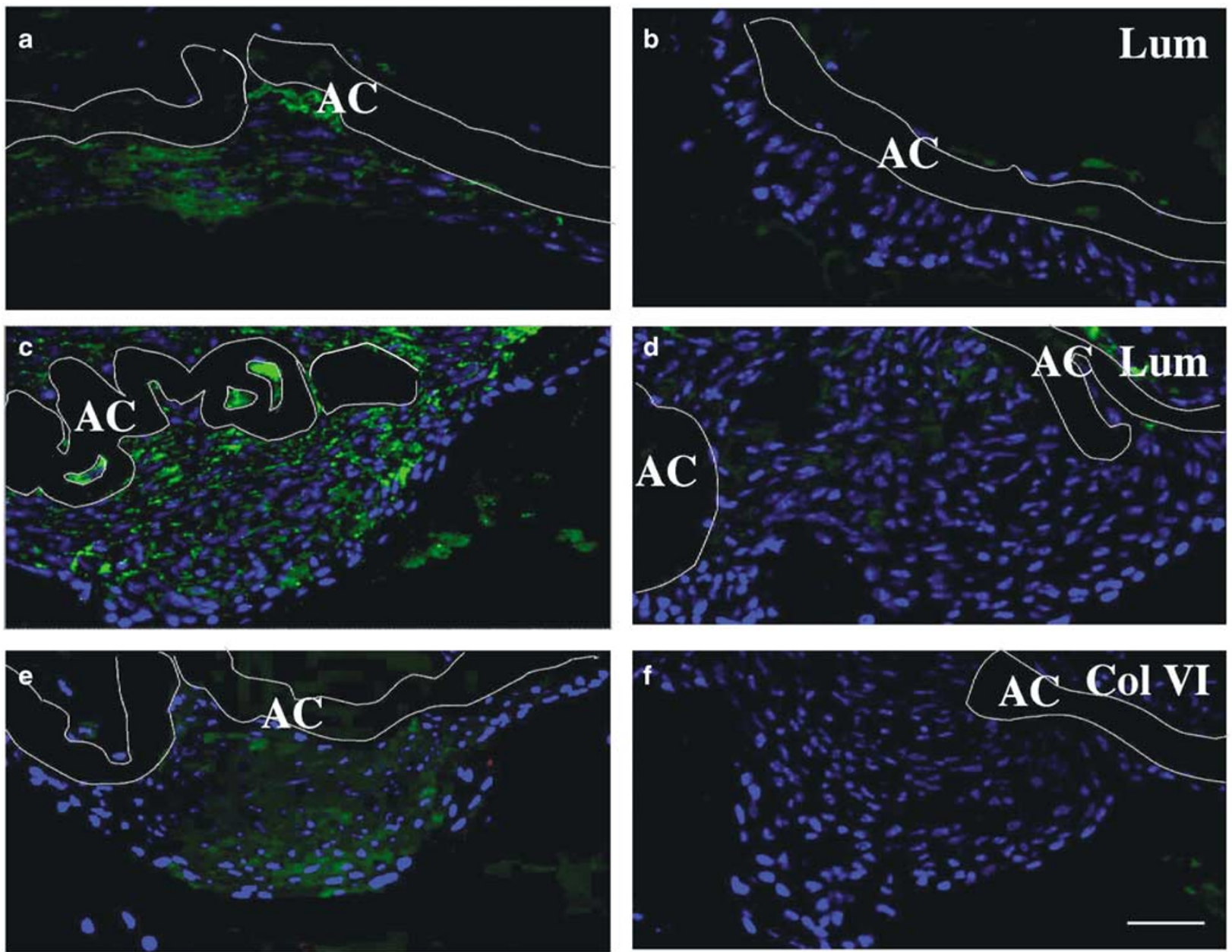

Figure 5 Expression of extracellular matrix components, lumican and collagen type VI, in epithelial cells of the injured lens. Frames a and $\mathbf{b}$ show staining of the specimens at day 5 , and frames $\mathbf{c}-\mathbf{f}$ at day 10 . At days 5 and 10, multilayered lens epithelial cells in control, CAG/Cre-carrying adenovirus-infected specimens, are labeled with antilumican antibody (a,c), while at day 5 no lumican immunoreactivity is detected in epithelial cells of the lens coinfected with CAG/Cre-carrying adenovirus and LNL/Smad7-carrying adenovirus (b) and at day 10 very faint lumican immunoreactivity is observed in these cells of the lens (d). Collagen type VI is detected in the cell multilayer in control specimens (e), but not in that of the lens coinfected with CAG/Cre-carrying adenovirus and LNL/Smad7carrying adenovirus (f). Dotted lines indicate anterior capsule; bar, $40 \mu \mathrm{m}$.

Clinically, after-cataract tissue is characterized by fibrous opacification and regeneration of lenticular fibers of Sommerring's ring and Elschnig's pearl formation, and is accompanied by lens epithelial cell proliferation. ${ }^{8}$ Using dominant-negative TGF $\beta$ receptor expression driven by the $\alpha$-crystallin promoter, de Iongh et $a l^{47}$ reported that lenticular fiber cells require TGF $\beta$ isoforms for lens fiber maturation during development. However, it is not known as to which signaling cascade(s) is (are) used because the TGF $\beta$ receptor potentially activates both Smad and non-Smad signaling cascades, that is, MAPK-Erk pathway, p38MAPK, or c-Jun-Nterminal kinase cascade. ${ }^{27,48}$ This is further supported by detection of both TGF $\beta$ receptors types I and II in postoperative lens epithelial cells in the equator region of the residual lens capsule. We have reported that elongated, fiber-differentiating, lens cells lack nuclear Smad3/4, suggesting that postoperative fiber regeneration does not require TGF $\beta$ signaling or is controlled by non-Smaddependent TGF $\beta$ signaling. ${ }^{15}$ Thus, it is of interest to examine if postoperative lens fiber regeneration is effectively blocked by Smad7 cDNA, although another animal model will be needed to answer this question.

In conclusion, lens capsular contraction by fibrosis is clinically unfavorable and blocking Smad signaling, in association with a therapy to suppress cell proliferation, may be a strategy to prevent this clinical problem. In injury-induced cell proliferation in lens epithelium, we have shown that loss of fibroblast growth factor 2 (FGF2) reduces cell proliferation, whereas it does not affect the physiological proliferation in an intact mouse lens. This result suggests that blocking FGF2 activity might be potentially used to suppress an abnormal cell proliferation in an 

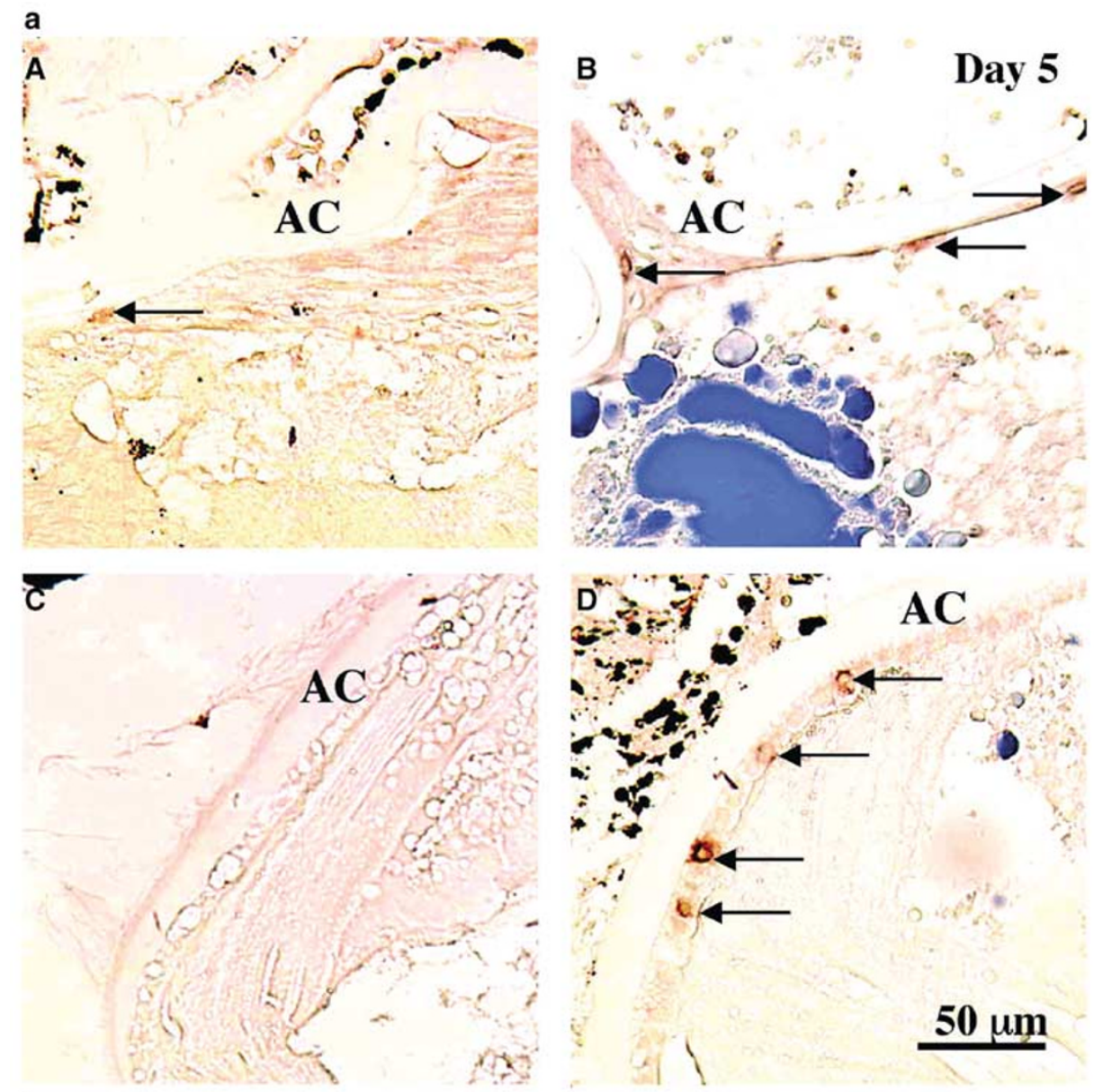

b

\section{$\mathbf{P}<\mathbf{0 . 0 0 5}$}

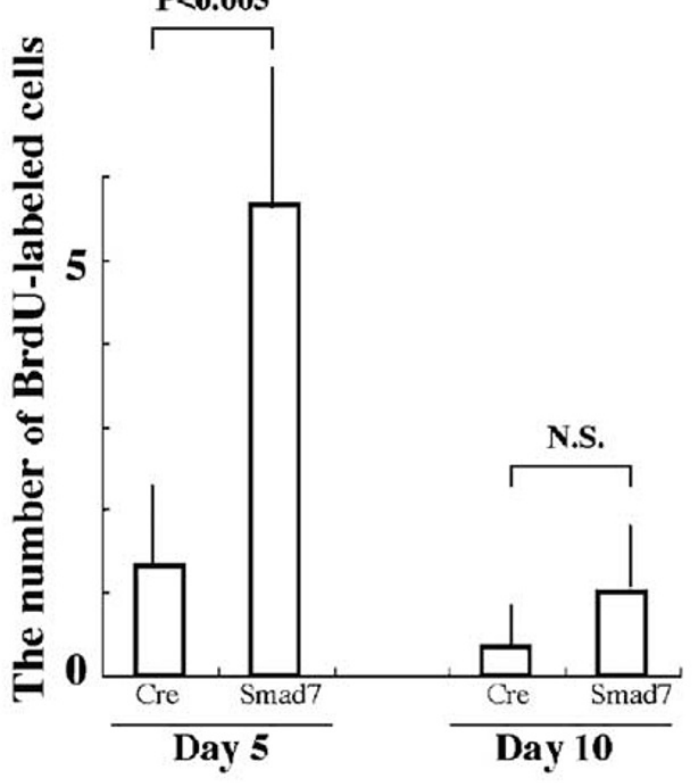

Figure 6 Cell proliferation in injured lens. (a), (A) Immunohistochemical detection of BrdU-labeled nuclei of cells in an injured lens that had received Cre- (A, C) or Smad7 (B,D)-adenovirus at day 5 postinjury. A BrdU-labeled cell nucleus (arrow) is observed in the cell multilayer formed beneath the broken anterior capsule (A), whereas no cells with a BrdU-labeled nucleus are seen in the equatorial region (C). In contrast, BrdU-positive nuclei (arrows) are observed beneath the anterior capsule (B) and in the equatorial epithelium (D) in lenses expressing Smad7. Bar, $50 \mu \mathrm{m}$. (b) Bar chart of the cells with BrdU-positive nuclei in injured lenses of either Cre- or Smad7adenovirus group at days 5 and 10. At day 5 , the mean number of cells with BrdU-positive nuclei is significantly $(P<0.005)$ higher in the Smad7-adenovirus group than in the Cre-adenovirus group at day 5 , but there is no significant difference in the number of labeled cells at day 10. 

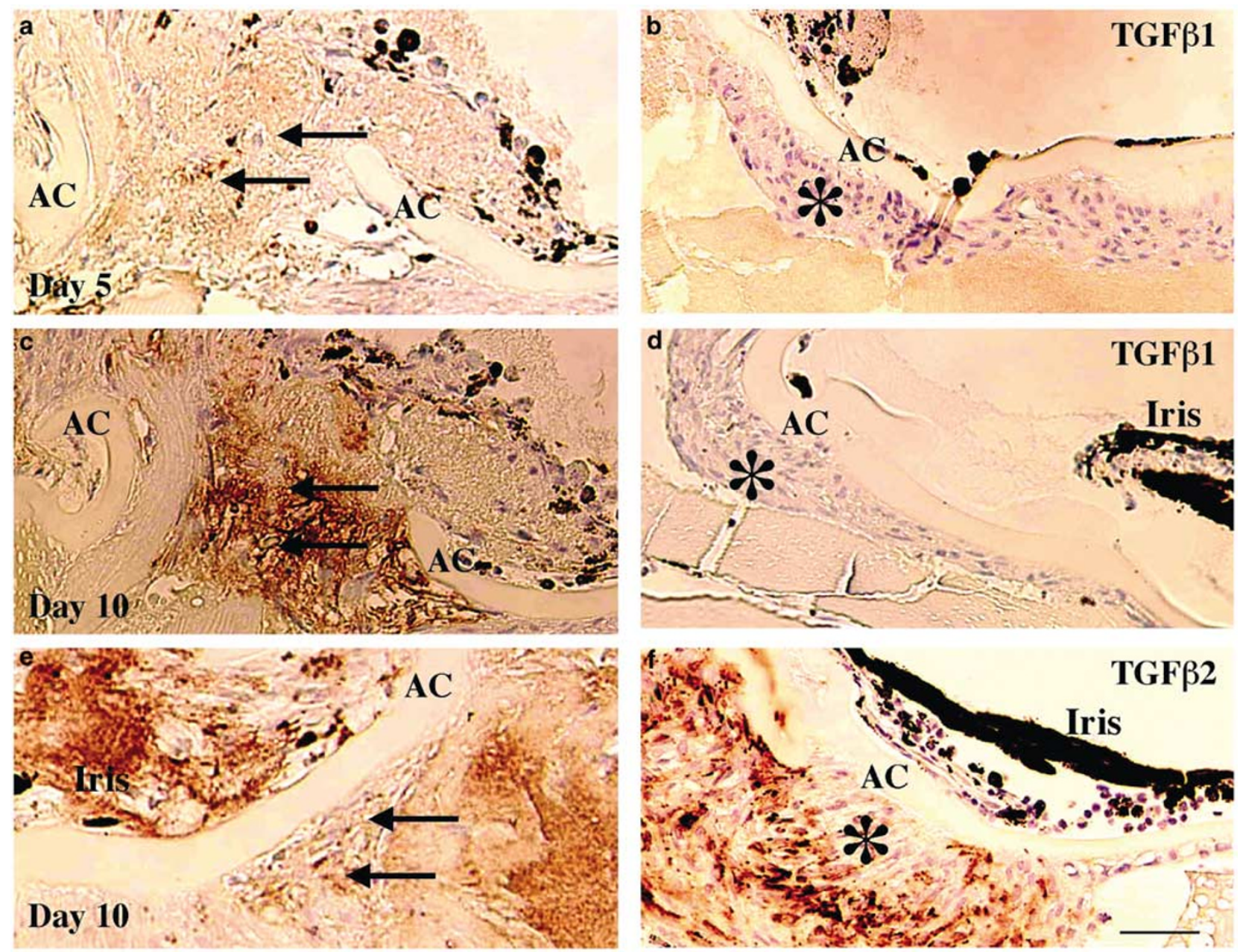

Figure 7 Protein expression pattern of transforming growth factor $\beta 1$ and $\beta 2$ (TGF $\beta 1$ and $\beta 2$ ) in injured lenses. TGF $\beta 1$ protein is upregulated in anterior lens epithelial cells with a fibroblastic appearance adjacent to the capsular break at day 5 (a, arrows) and is more intensely expressed there at day 10 (c, arrows) in control lenses, while it is not detected in multilayered lens epithelial cells (asterisks) around the break in Smad7 gene-transferred lenses at day 5 (b) and 10 (d). TGF $\beta 2$ is expressed in peripheral lens epithelium, but not in anterior epithelium in an uninjured lens (not shown). TGF $\beta 2$ is then upregulated postinjury at day 5 (not shown) and day 10 (e, f) in both control (e, arrows) and Smad7 gene-transfer specimens (f, asterisk); bar, $40 \mu \mathrm{m}$.

injured lens epithelium induced by blocking Smad signaling to prevent fibrosis.

\section{Acknowledgements}

This study was supported by a grant from the Ministry of Education, Science, Sports and Culture of Japan and Uehara Memorial Foundation (to SS), and a Research Grant on Priority Areas from Wakayama Medical University (to SSYM and AO).

\section{References}

1 Hay ED. An overview of epithelio-mesenchymal transformation. Acta Anat (Basel) 1995;154:8-20.
2 Savagner P. Leaving the neighborhood: molecular mechanisms involved during epithelial-mesenchymal transition. Bioessays 2001;23:912-923.

3 Thiery JP. Epithelial-mesenchymal transitions in development and pathologies. Curr Opin Cell Biol 2003;15:740-746.

4 Kalluri R, Neilson EG. Epithelial-mesenchymal transition and its implications for fibrosis. J Clin Invest 2003;112:1776-1784.

5 Saika S, Kawashima Y, Miyamoto T, et al. Immunolocalization of prolyl 4-hydroxylase subunits, $\alpha$-smooth muscle actin, and extracellular matrix components in human lens capsules with lens implants. Exp Eye Res 1998;66:283-294.

6 Marcantonio JM, Vrensen GF. Cell biology of posterior capsular opacification. Eye 1999;13:484-488.

7 Saika S, Okada Y, Miyamoto T, et al. Smad translocation and growth suppression in lens epithelial cells by endogenous TGF $\beta 2$ during wound repair. Exp Eye Res 2001;72:679-686. 
8 Saika S. Relationship between posterior capsular opacification and intraocular lens biocompatibility. Prog Ret Eye Res 2004;23:283-305.

9 Jampel HD, Roche N, Stark WJ, et al. Transforming growth factor- $\beta$ in human aqueous humor. Curr Eye Res 1990;9:963-969.

10 Connor Jr TB, Roberts AB, Sporn MB, et al. Correlation of fibrosis and transforming growth factor- $\beta$ type 2 levels in the eye. J Clin Invest 1989;83:1661-1666.

11 Saika S, Miyamoto T, Tanaka S, et al. Response of lens epithelial cells to injury: role of lumican in epithelialmesenchymal transition. Invest Ophthalmol Vis Sci 2003;44:2094-2102.

12 Srinivasan Y, Lovicu FJ, Overbeek PA. Lens-specific expression of transforming growth factor $\beta 1$ in transgenic mice causes anterior subcapsular cataracts. J Clin Invest 1998;101:625-634.

13 Gordon-Thomson C, de Iongh RU, Hales AM, et al. Differential cataractogenic potency of TGF- $\beta 1,-\beta 2$, and $-\beta 3$ and their expression in the postnatal rat eye. Invest Ophthalmol Vis Sci 1998;39:1399-1409.

14 Wormstone IM, Tamiya S, Anderson I, et al. TGF- $\beta 2$ induced matrix modification and cell transdifferentiation in the human lens capsular bag. Invest Ophthalmol Vis Sci 2002;43:2301-2308.

15 Saika S, Miyamoto T, Ishida I, et al. TGF $\beta /$ Smad signalling in postoperative human lens epithelial cells. Br J Ophthalmol 2002;86:1428-1433.

16 Sato M, Muragaki Y, Saika S, et al. Targeted disruption of TGF- $\beta 1 / \mathrm{Smad} 3$ signaling protects against renal tubulointerstitial fibrosis induced by unilateral ureteral obstruction. J Clin Invest 2003;112:1486-1494.

17 Saika S, Kono-Saika S, Ohnishi Y, et al. Smad3 signaling is required for epithelial-mesenchymal transition of lens epithelium after injury. Am J Pathol 2004;164:651-663.

18 Piek E, Moustakas A, Kurisaki A, et al. TGF- $\beta$ type I receptor/ALK-5 and Smad proteins mediate epithelial to mesenchymal transdifferentiation in NMuMG breast epithelial cells. J Cell Sci 1999;112:4557-4568.

19 Oft M, Akhurst RJ, Balmain A. Metastasis is driven by sequential elevation of $\mathrm{H}$-ras and Smad2 levels. Nat Cell Biol 2002;4:487-494.

20 Bakin AV, Tomlinson AK, Bhowmick NA, et al. Phosphatidylinositol 3-kinase function is required for transforming growth factor $\beta$-mediated epithelial to mesenchymal transition and cell migration. J Biol Chem 2000;275:36803-36810.

21 Bhowmick NA, Ghiassi M, Bakin A, et al. Transforming growth factor- $\beta 1$ mediates epithelial to mesenchymal transdifferentiation through a RhoA-dependent mechanism. Mol Biol Cell 2001;12:27-36.

22 Bhowmick NA, Zent R, Ghiassi $\mathrm{M}$, et al. Integrin $\beta 1$ signaling is necessary for transforming growth factorbeta activation of p38MAPK and epithelial plasticity. J Biol Chem 2001;276:46707-46713.

23 Itoh S, Thorikay M, Kowanetz M, et al. Elucidation of Smad requirement in transforming growth factor-beta type I receptor-induced responses. J Biol Chem 2003;278:3751-3761.

24 Moustakas A, Pardali K, Gaal A, et al. Mechanisms of TGF- $\beta$ signaling in regulation of cell growth and differentiation. Immunol Lett 2002;82:85-91.

25 ten Dijke P, Goumans MJ, Itoh F, et al. Regulation of cell proliferation by Smad proteins. J Cell Physiol 2002;191:1-16.
26 Massague J, Wotton D. Transcriptional control by the TGF- $\beta /$ Smad signaling system. EMBO J 2000;19:17451754.

27 Derynck R, Zhang YE. Smad-dependent and Smadindependent pathways in TGF- $\beta$ family signaling. Nature 2003;425:577-584

28 Nakao A, Fujii M, Matsumura R, et al. Transient gene transfer and expression of Smad7 prevents bleomycininduced lung fibrosis in mice. J Clin Invest 1999;104:5-11.

29 Lan $\mathrm{HY}, \mathrm{Mu} \mathrm{W}$, Tomita $\mathrm{N}$, et al. Inhibition of renal fibrosis by gene transfer of inducible Smad7 using ultrasound-microbubble system in rat UUO model. J Am Soc Nephrol 2003;14:1535-1548.

30 Dooley S, Hamzavi J, Breitkopf K, et al. Smad7 prevents activation of hepatic stellate cells and liver fibrosis in rats. Gastroenterology 2003;125:178-191.

31 Sato Y, Tanaka K, Lee G, et al. Enhanced and specific gene expression via tissue-specific production of Cre recombinase using adenovirus vector. Biochem Biophys Res Commun 1998;244:455-462.

32 Miyake K, Tohyama T, Shimada T. Two-step gene transfer using an adenoviral vector carrying the CD4 gene and human immunodeficiency viral vectors. Hum Gene Ther 1996;7:2281-2286.

33 Kanegae Y, Miyake S, Sato Y, et al. Adenovirus vector technology: an efficient method for constructing recombinant adenovirus and on/off switching of gene expression. Acta Paediatr Jpn 1996;38:182-188.

34 Carver EA, Jiang R, Lan Y, et al. The mouse snail gene encodes a key regulator of the epithelial-mesenchymal transition. Mol Cell Biol 2001;21:8184-8188.

35 Nieto MA. The snail superfamily of zinc-finger transcription factors. Nat Rev Mol Cell Biol 2002; 3:155-166

36 Cano A, Perez-Moreno MA, Rodrigo I, et al. The transcription factor snail controls epithelial-mesenchymal transitions by repressing E-cadherin expression. Nat Cell Biol 2000;2:76-83.

37 Flanders KC, Ludecke G, Engels S, et al. Localization and actions of transforming growth factors-beta in the embryonic nervous system. Development 1991; 113:183-191.

38 Saika S, Saika S, Liu CY, et al. TGF $\beta 2$ in corneal morphogenesis during mouse embryonic development. Dev Biol 2001;240:419-432.

39 Yang YC, Piek E, Zavadil J, et al. Hierarchical model of gene regulation by transforming growth factor- $\beta$. Proc Natl Acad Sci USA 2003;100:10269-10274.

40 Piek E, Ju WJ, Heyer J, et al. Functional characterization of transforming growth factor $\beta$ signaling in Smad2- and Smad3-deficient fibroblasts. J Biol Chem 2001;276:19945-19953.

41 Flanders KC, Sullivan CD, Fujii M, et al. Mice lacking Smad3 are protected against cutaneous injury induced by ionizing radiation. Am J Pathol 2002;160:10571068.

42 Evans RA, Tian YC, Steadman R, et al. TGF- $\beta 1-$ mediated fibroblast-myofibroblast terminal differentiation-the role of Smad proteins. Exp Cell Res 2003;282:90-100.

43 Schnabl B, Kweon YO, Frederick JP, et al. The role of Smad3 in mediating mouse hepatic stellate cell activation. Hepatology 2001;34:89-100.

44 Serini G, Gabbiani G. Mechanisms of myofibroblast activity and phenotypic modulation. Exp Cell Res 1999;250:273-283. 
45 Serini G, Bochaton-Piallat ML, Ropraz P, et al. The fibronectin domain ED-A is crucial for myofibroblastic phenotype induction by transforming growth factorbeta1. J Cell Biol 1998;142:873-881.

46 Ashcroft GS, Yang X, Glick AB, et al. Mice lacking Smad3 show accelerated wound healing and an impaired local inflammatory response. Nat Cell Biol 1999;1:260-266.
47 de Iongh RU, Lovicu FJ, Overbeek PA, et al. Requirement for TGF $\beta$ receptor signaling during terminal lens fiber differentiation. Development 2001;128:39954010.

$48 \mathrm{Yu}$ L, Hebert MC, Zhang YE. TGF- $\beta$ receptor-activated p38 MAP kinase mediates Smad-independent TGF- $\beta$ responses. EMBO J 2002;21:3749-3759. 